\title{
KILAT
}

Vol. 10, No. 1, April 2021, P-ISSN 2089-1245, E-ISSN 2655-4925

DOI: https://doi.org/10.33322/kilat.v10i1.1128

\section{Pemanfaatan Bioretensi Buatan Sebagai Upaya Pengelolaan Air Hujan Untuk Peningkatan Kualitas Air}

\author{
Endah Lestari $^{\text {; }}$ Budi Wicaksono ${ }^{2}$; RR. Mekar Ageng Kinasti ${ }^{3}$ \\ 1, 2, 3 Institut Teknologi PLN \\ ${ }^{1}$ endahlestari@itpln.ac.id
}

\begin{abstract}
Water treatment priority water resources that are approved for air retention, Increased peak flow and improved water quality with regard to nutrients, pollutants, heavy metals and sediments. Bioretensi system is one alternative in improving air quality from rainwater runoff and reducing peak loads which also reduces runoff volume due to rain water.Management of urban water resources must be adapted to local conditions and sustainable. Bioretensi is a local infiltration media consisting of mixed soil and vegetation to absorb and manage rainwater so that it does not direct to the air body.

The study was approved by the experimental research carried out with further research namely Bucket Bioretensi Design, installation, and testing. Some of the tests conducted on Bucket Bioretensi are rainwater quality testing, studying the level of infiltration by comparing the volume of inflows when opening a biretensi box and the volume of exits after going through a Bucket Bioretency. Bioretensi Bucket is made from used jerry cans with a capacity of 20 liters with dimensions of $27 \mathrm{~cm}$ $x 23 \mathrm{~cm} \times 37 \mathrm{~cm}$. Material obtained from high density polyethylene HDPE.

After experimenting, the results of physical water observations show that the Bioretension Technique in the form of a bucket bioretition, produces water that tends to be clearer on filtering at week III than at the beginning of filtering in weeks I and II.
\end{abstract}

Keywords: Rainwater management, bioretency, runoff, vegetation, drainage

\begin{abstract}
ABSTRAK
Pengolahan sumber daya air terutama air hujan yang berfokus pada retensi air, pengurangan aliran puncak dan peningkatan kualitas air berkenaan nutrisi, polutan, logam berat dan sedimen. Sistem Bioretensi adalah salah satu alternatif dalam peningkatan kualitas air dari limpasan air hujan dan mengurangi beban puncak yang mengakibatkan berkurang pula volume limpasan akibat air hujan. Pengelolaan sumber daya air perkotaan harus disesuaikan secara iklim dengan kondisi lokal dan secara berkelanjutan. Bioretensi merupakan media infitrasi lokal yang terdiri dari tanah dan vegetasi campuran untuk menyerapkan dan mengelola air hujan agar tidak langsung mengatus ke badan air.

Penelitian direncanakan secara experimental dilakukan dengan tahapan penelitian yaitu perancangan Bioretensi Bucket, pemasangan, dan pengujian. Beberapa pengujian yang dilakukan pada Bioretensi Bucket adalah pengujian kualitas air hujan, mengetahui tingkat infiltrasi dengan perbandingan volume debit inflow saat memasuki kotak biretensi dan volume outflow setelah melalui Bioretensi Bucket. Bioretensi Bucket terbuat dari tangki jerigen bekas dengan kapasitas 20 liter dengan dimensi $27 \mathrm{~cm} \times 23 \mathrm{~cm} \times 37 \mathrm{~cm}$. Material berasal dari HDPE High density polyethylene.

Setelah melalui percobaan dari hasil pengamatan air secara fisik memperlihatkan bahwa Teknik Bioretensi yang berupa bioretensi bucket, menghasilkan air yang cenderung lebih jernih pada penyaringan di minggu ke III dibandingkan pada awal-awal penyaringan di minggu I dan II.
\end{abstract}

Kata kunci : Manajemen air hujan, bioretensi, limpasan,, vegetasi, drainase 


\section{PENDAHULUAN}

\subsection{Latar Belakang}

Pertumbuhan penduduk daerah perkotaan di Indonesia dari tahun 1950 - 2010 selalu meningkat dengan laju peningkatan antara $1.4-2.6 \%$ setiap tahunnya. Hasil sensus penduduk tahun 2010, jumlah penduduk Indonesia adalah 238 juta dibanding dengan jumlahnya pada tahun 1950 yang hanya 77 juta (http://www.bps.go.id).

Peningkatan pertumbuhan penduduk akan bertambah tiap tahunnya yang akan berakibat pada pengadaan area perkotaan. Pertumbuhan di kota-kota terutama disebabkan oleh migrasi pedesaan ke daerah perkotaan di negara berkembang dan pengembangan pinggiran kota di negara maju. Pembangunan perkotaan menyebabkan berbagai dampak yang terkait dengan pelayanan populasi manusia, peningkatan penarikan air tawar dari air tanah untuk memenuhi kebutuhan, peningkatan muatan air limbah di area saluran pembuangan dan banyak lagi [1].

Jika tidak ada perubahan dalam pola urbanisasi dan pengembangan kota, maka otomatis akan meningkatkan daerah-daerah kedap air di kota-kota besar. Hal ini akan mengakibatkan efek yang dramatis dari peningkatan volume limpasan (run-off) di perkotaan dan penurunan kualitas air drainase perkotaan.

Pola manajemen pengelolaan air hujan di daerah perkotaan berubah seiring dengan waktu. Cara-cara pengelolaan secara konvensional pada umumnya masih sering dilakukan. Konsep drainase yang diartikan sebagai upaya pengatusan air secepat-cepatnya ke sungai dan selanjutnya ke hilir akan meningkatkan beban sungai semakin besar yang justru akan mengakibatkan bencana banjir akan terjadi di daerah hilir [2].

Selama beberapa dekade terakhir terdapat permasalahan lain selain resiko banjir yaitu masalah penurunan kualitas air hujan karena daerah tangkapan hujan/atap yang menyebabkan air terkontaminasi.. Perubahan fisik pada air adalah yang paling mudah diamati, seperti berubahnya tingkat kejernihan air, serta perubahan warna dan rasa air. Belum lagi perubahan kimia yang juga dapat terjadi pada air seperti perubahan $\mathrm{pH}$ (tingkat keasaman).

Perlu adanya pengelolaan air hujan yang lebih baik khususnya di perkotaan untuk mengurangi meningkatnya tekanan yang diterima oleh sistem saluran pembuangan. Konsep pengelolaan air hujan (stormwater) berkelanjutan juga mengarah pada pengembangan kriteria dan evaluasi pengelolaan air hujan (stormwater) terpisah dibandingkan dengan saluran pembuangan gabungan sehubungan dengan keberlanjutan. Konsep Eko-Drainase atau disebut juga drainase yang berwawasan lingkungan dapat diartikan sebagai usaha membuang/mengalirkan air kelebihan ke sungai dengan waktu seoptimal mungkin sehingga tidak menyebabkan terjadinya masalah kesehatan dan masalah banjir [3]. Lindholm dan Noreide menemukan sistem pengelolaan air hujan (stormwater) berbasis alami menjadi 4-5\% lebih berkelanjutan daripada sistem saluran pembuangan gabungan konvensional. Sistem alami memperoleh nilai logam yang lebih baik dalam lumpur/sedimen, biaya, operasi, dan nilai lanskap untuk rekreasi [4].

Tujuan dari penelitian ini adalah untuk merencanakan pengelolaan air hujan dengan membuat sistem Bioretensi Buatan vegetasi yang sesuai dengan iklim tropis guna mengontrol kualitas air dari drainase-drainase perkotaan yang ramah lingkungan dan berteknologi tepat guna.

\subsection{Rumusan Masalah}

Dengan meningkatnya volume limpasan (runoff) daerah perkotaan dan penurunan pada kualitas air pada drainase kota akibat dari pengaruh urbanisasi dan pengembangan wilayah perkotaan (urban development), maka diperlukan adanya teknologi terbarukan. 


\section{KILAT}

Vol. 10, No. 1, April 2021, P-ISSN 2089-1245, E-ISSN 2655-4925

DOI: https://doi.org/10.33322/kilat.v10i1.1128

Sistem Bioretensi sebagai salah satu metode pembangunan berdampak rendah LID (low impact development) yang mengupayakan dalam pencegahan terhadap penurunan kualitas air.

Maka rumusan masalah pada penelitian ini adalah:

- Bagaimana sistem Bioretensi sebagai salah satu cara dalam pengelolaan sumber daya air yang ramah lingkungan dan tepat guna serta berkelanjutan?

- Bagaimana desain/rancangan sistem Bioretensi yang sesuai diaplikasikan pada wilayah penelitian?

- Bagaimana sistem rancangan Bioretensi dapat memperbaharui kualitas air dari drainase kota?

\subsection{Kajian Literatur}

Bioretention adalah praktik manajemen kuantitas dan kualitas air yang mengandalkan proses hidrologis, kimia, fisik, dan biologis yang terjadi pada komponen tanaman, tanah, dan mikroorganisme terpadu untuk mengurangi volume dan aliran puncak limpasan air hujan dan menghilangkan polutan dari limpasan air hujan [5].

Bioretensi adalah bagian dari Infastruktur Hijau (Green Infrastructure) yang digunakan untuk menangani limpasan perkotaan pada sumbernya. Teknologi GI mempertahankan volume limpasan, aliran puncak, dan waktu untuk aliran puncak di daerah perkotaan secara konsisten menggunakan infiltrasi, retensi, penyimpanan, dan langkah-langkah pengelolaan air hujan lainnya [6].

Sistem bioretensi dapat dikonfigurasikan sebagai bak bioretensi atau lebih panjang, lebih sempit (sengkedan bioretensi). Secara umum, cekungan bioretensi memiliki dasar datar sedangkan sengkedan bioretensi mungkin memiliki bagian bawah yang miring. Kedalaman penyimpanan limpasan di atas permukaan lapisan tanah biasanya dangkal. Sistem Bioretensi dapat menghilangkan TSS (Total Suspended Solids) 80-90 \%, tergantung pada ketebalan lapisan media tanam dan jenis vegetasi yang ditanam [7].

Media adalah faktor kunci dalam desain bioretensi. Kriteria seleksi dimaksudkan untuk meningkatkan pengurangan limpasan dan kinerja pembuangan bioretention dan mengatasi kondisi lokal. Secara umum, suatu bioretention idealnya mengandung sekitar $50 \%-60 \%$ pasir dan $40 \%-50 \%$ campuran lempung/lempung pasir berdasarkan volume per volume. Kandungan tanah liat harus diminimalkan untuk mempertahankan hidrologi sel yang tepat, idealnya dalam kisaran $5 \%-8 \%$. Media dengan tanah liat yang terlalu banyak dapat mengurangi infiltrasi ke dalam media [1].

Sistem bioretensi merupakan sistem pengelolaan air hujan tradisional yang dapat dengan mudah dipelihara dan dipantau dan tidak memerlukan praktik atau pedoman pengelolaan khusus [8].

Sistem Bioretention adalah fasilitas pengolahan air hujan pada wilayah perkotaan yang berdampak rendah (Low Impact Development) yang memberikan retensi dan konversi polutan serta retensi air dengan meniru fungsi tanah alami [9].

Terdapat beberapa tipe dari sistem bioretensi, diantaranya yaitu:

a. Cekungan Bioretensi (Basins Bioretention)

Cekungan Bioretention adalah daerah bervegetasi berupa cekungan dimana limpasan disaring melalui lapisan media filter (contohnya: lempung berpasir) lalu merembes ke bawah. Kemudian air dikumpulkan melalui pipa saluran air (perforated pipes) dan mengalir masuk ke saluran air di hilir atau air dapat dimasukkan pada penampungan untuk dapat digunakan sebagai kebutuhan baku yang akan melalui proses selanjutnya [10].

Best Management Practices (BMP) atau Low Impact Development (LID) memerlukan strategi desentralisasi yang bertujuan untuk memulihkan fitur hidrologi pra-pengembangan melalui penahanan dan penanganan limpasan yang tercemar dari sumbernya [11]. 




Gambar 1. Potongan Desain Basins Bioretention di lingkungan perumahan

\section{a. Sengkedan Bioretensi (Bioretention Swales)}

Sengkedan Bioretensi adalah daerah vegetasi berupa saluran terbuka yang berfungsi untuk pengelolaan dan pengaliran air hujan. Menggabungkan sistem bioretensi yang dipasang/install di dasar sengkedan untuk mengalirkan aliran air hujan sebagai bagian dari sebuah sistem drainase yang kecil dan atau besar.

Karena efek logam yang berpotensi toksik pada organisme pada air hujan di daerah berkembang perkotaan, pembuangan logam yang berasal dari air hujan menjadi perhatian utama. Konsentrasi limbah logam bioretensi dan/atau penghilangan logam telah diuji dalam studi manifold, yang menunjukkan bahwa penghilangan logam total secara umum efisien, seringkali melebihi 80 90\% [9].

Sampel kualitas air limbah bioretensi menunjukkan penurunan yang signifikan ( $\mathrm{p}<0,05)$ pada berbagai polutan, termasuk bakteri indikator. Untuk bakteri indikator, bioretensi menunjukkan penghapusan E. coli secara keseluruhan sebesar 49\% [12].

Sistem bioretensi dalam skala lokal di Universiti Tenaga Nasional Malaysia adalah studi percontohan yang dapat berfungsi sebagai solusi terintegrasi yang efektif dan hebat untuk meningkatkan polusi air hujan perkotaan. Hasil penelitian menunjukkan bahwa sistem bioretensi memiliki kemampuan untuk menghilangkan Total Suspended Solid (TSS), Total Phosphorus (TP) and Total Nitrogen (TN) secara signifikan [13].

\section{METODE PENELITIAN}

\subsection{Tahapan Penelitian}

Penelitian dilakukan secara experimental dalam hal ini pengujian dilakukan secara langsung. Dengan menggunakan air hujan yang ditampung di dalam tangki air hujan lalu air hujan dimasukkan ke dalam modul Bioretensi buatan. Terdapat 3 (tiga) buah bak bioretensi yang akan dimasukkan oleh air hujan, masing-masing bak bioretensi berisi media tanam yang berbeda prosentasenya.

Adapun tahap-tahapan penelitian yang dilakukan adalah sebagai berikut:

1. Tahapan Persiapan yang meliputi studi literatur mengenai konsep-konsep dan teori Bioretensi dalam upaya peningkatan kualitas air hujan. Pengumpulan data yang berupa data curah hujan 15 tahunan, luas daerah tangkapan hujan dan debit limpasan yang dihasilkan di wilayah penelitian. 


\section{KILAT}

Vol. 10, No. 1, April 2021, P-ISSN 2089-1245, E-ISSN 2655-4925

DOI: https://doi.org/10.33322/kilat.v10i1.1128

Persiapan alat dan bahan/material yang akan digunakan untuk membuat bak bioretensi. Adapun bahan-bahan yang akan digunakan adalah berupa jerigen bekas dengan kapasitas 20 liter, pasir kuarsa, (aggregate kasar) kerikil ukuran split, ijuk, tanah dan mulsa (tanaman kering).

2. Tahap Pembuatan Bioretensi Buatan

Pembuatan desain Bioretensi buatan yang dapat dipindah-pindah (mobile) agar dapat digunakan di beberapa lokasi yang disesuaikan dengan wilayah-wilayah penelitian dengan instalasi yang mudah dan dapat dihubungkan pada tangki penampungan air hujan dan atau pada sumur resapan.

Pembuatan Bioretensi Buatan dilakukan dengan menggunakan jerigen bekas kapasitas 20 liter dengan dimensi panjang $\mathrm{x}$ lebar $\mathrm{x}$ tinggi adalah $27 \mathrm{~cm} \times 23 \mathrm{~cm} \times 37 \mathrm{~cm}$. Material jerigen berasal dari HDPE High density polyethylene.

3. Pengujian Bioretensi Buatan

Untuk pengujian Bioretensi buatan dapat dilakukan pada air dalam tangki penampungan hujan.

4. Analisa Hasil dan Pembahasan

Setelah didapatkan hasil pengujian Bioretensi kemudian akan dilakukan analisa dan pembahasan mengenai kualitas air serta volume limpasan setelah setelah melalui modul Bioretensi.

\section{HASIL DAN PEMBAHASAN}

\subsection{Analisa Hidrologi}

Dalam perancanaan pemodelan Bioretensi sama dengan perencanaan bangunan-bangunan air lainnya yang juga memerlukan data curah hujan. Analisa hidrologi yang berupa data curah hujan untuk digunakan dalam menghitung intensitas hujan jam-jaman, agar dapat diketahui jumlah volume limpasan air hujan yang dihasilkan di wilayah penelitian.

Data curah hujan didapatkan dari 5 stasiun hujan yaitu stasiun hujan Cibinong, stasiun hujan Cawang, stasiun hujan Pulogadung, stasiun hujan Sunter Kodamar, Sunter III Rawa Badak. Data hujan yang digunakan adalah hasil pencatatan hujan 15 tahun sejak Januari 2004 sampai Desember 2018. Perhitungan curah hujan maksimum selama 15 tahun disajikan pada tabel 1 .

Tabel 1. Tabel Curah Hujan Maksimum selama 15 tahun

\begin{tabular}{|c|c|}
\hline Tahun & Curah Hujan $(\mathrm{mm})$ \\
\hline 2004 & 65.592 \\
\hline 2005 & 105.746 \\
\hline 2006 & 52.993 \\
\hline 2007 & 73.299 \\
\hline 2008 & 92.619 \\
\hline 2009 & 43.923 \\
\hline 2010 & 43.319 \\
\hline 2011 & 72.264 \\
\hline 2012 & 53.394 \\
\hline 2013 & 59.966 \\
\hline
\end{tabular}




\begin{tabular}{|l|l|}
\hline 2014 & 59.836 \\
\hline 2015 & 88.906 \\
\hline 2016 & 75.715 \\
\hline 2017 & 74.426 \\
\hline 2018 & 76.776 \\
\hline
\end{tabular}

Untuk grafik yang menunjukkan curah hujan maksimum tahunan selama 15 tahun ditunjukkan pada gambar 1 dibawah ini



Gambar 2. Grafik Hujan Maksimum Tahunan di 5 stasiun Hujan

Dari data hujan yang didapatkan diatas maka akan didapatkan intensitas hujan jam-jaman maksimum di wilayah penelitian adalah $11,50 \mathrm{~mm} / \mathrm{jam}$.

\subsection{Daerah Tangkapan Air}

Wilayah penelitian memiliki 4unit bangunan atau disebut juga daerah tangkapan air/catchment area impermeable (lapisan keras/tidak dapat meresap air) dapat dilihat pada gambar 5.3. Adapun bangunan-bangunan tersebut adalah sebagai berikut:
1. Area Kantin
: $184 \mathrm{~m}^{2}$ (Area Tertutup)
2. Bangunan Masjid
: $143 \mathrm{~m}^{2}$ (Area Tertutup)
3. Gedung Pembelajaran
: 866,38 $\mathrm{m}^{2}$ (Area Tertutup)
4. Lapangan Upacara
: $730 \mathrm{~m}^{2}$ (Area Terbuka) 


\section{KILAT}

Vol. 10, No. 1, April 2021, P-ISSN 2089-1245, E-ISSN 2655-4925

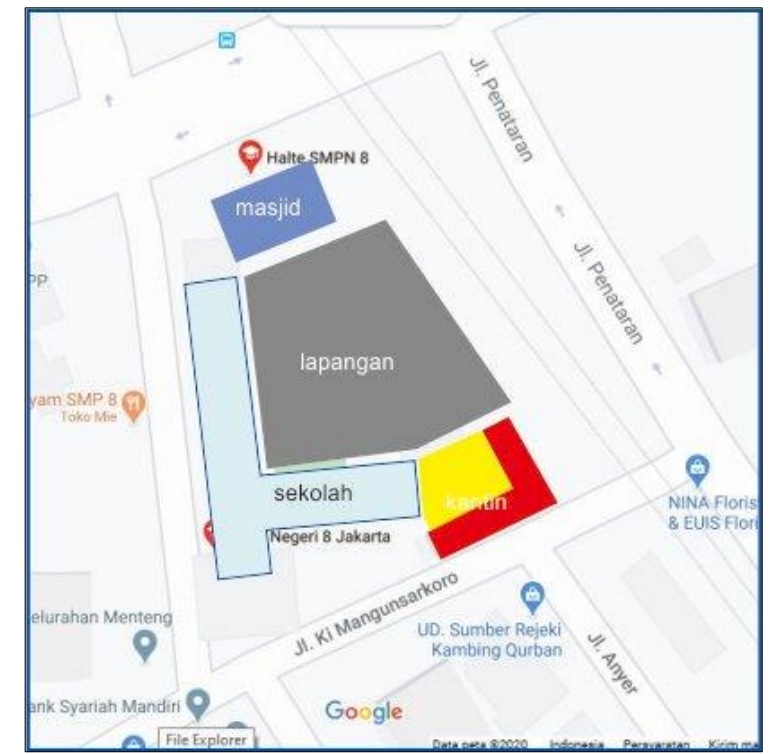

Gambar 3. Unit-unit Bangunan pada wilayah penelitian

\subsection{Volume Total Limpasan Air Hujan}

Untuk menghitung total volume limpasan air hujan yang diterima oleh wilayah penelitian memerlukan data-data sebagai berikut:

1. Daerah tangkapan hujan

- Total luas bangunan area tertutup $: 1.193,38 \mathrm{~m}^{2}$

- Total luas bangunan area terbuka $\quad: 730 \mathrm{~m}^{2}$

2. Intensitas Hujan

$: 11,50 \mathrm{~mm} / \mathrm{jam}$

3. Lamanya hujan : 2 jam (diambil rata-rata)

4. Koefisien Run-off

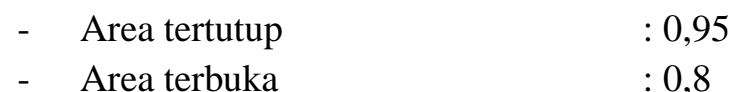

Dengan menggunakan rumus rasional maka didapatkan:

Area Tertutup: $\mathrm{Q}=0,003621 \mathrm{~m}^{3} /$ detik

Area Terbuka: $\mathrm{Q}=0,001865 \mathrm{~m}^{3} / \mathrm{detik}$

Maka, total limpasan/runoff $\quad=0,0050 \mathrm{~m}^{3} /$ detik

Maka, total volume limpasan/runoff = tingkat limpasan puncak $\mathrm{x}$ durasi/lamanya hujan

$$
\begin{aligned}
& =0,0050 \times 2 \times 3600 \\
& =39,434 \mathrm{~m}^{3} \\
& =39.434,4 \text { liter }
\end{aligned}
$$

\subsection{Bioretensi Bucket}

Bioretensi Bucket yang dibuat pada penelitian ini ada 2 tipe, Bioretensi Bucket yaitu yang bersifat fleksibel (moveable/dapat dipindah-pindah) dan Bioretensi Bucket permanen/underground. Skema Bioretensi Bucket model 1 dan model 2 dapat dilihat pada gambar 4. Sumber air yang akan dimasukkan ke dalam Bioretensi Bucket adalah yang berasal dari penampungan air hujan. 




Gambar 4. Skematik Desain Bioretensi Bucket Permanen dan Moveable

Bioretensi Bucket terbuat dari tangki jerigen bekas dengan kapasitas 20 liter. Pada bagian atasnya dipotong sedemikian rupa sehingga membentuk seperti ember kotak dengan dimensi panjang x lebar x tinggi adalah $27 \mathrm{~cm}$ x $23 \mathrm{~cm}$ x $37 \mathrm{~cm}$. Material jerigen berasal dari HDPE High density polyethylene.

Pada bagian bawah Bioretensi Bucket diberikan bukaan dan dihubungkan dengan kran air atau dengan pipa, yang berfungsi untuk mengalirkan air yang telah melewati Bioretensi Bucket [14]. Pipa dan kran air ini dipasang untuk mengukur aliran dan mengambil sample air yang telah melalui Bioretensi Bucket. Pipa dengan diameter 3 inchi lalu disambung dengan knee/socket dan disambung kembali dengan pipe $3 / 4$ inchi untuk mengalirkan limpasan ke dalam Bioretensi bucket sebagai aliran masuk.

Komposisi dari tiap Bioretensi Bucket adalah sebagai berikut:

Bioretensi Bucket I :

- Kerikil $1 \mathrm{~kg}(10 \mathrm{~cm})$

- Ijuk $5 \mathrm{~cm}$

- Pasir kuarsa 2 kg (5 cm)

- Tanah humus $5 \mathrm{~kg}(17 \mathrm{~cm})$

- Tanaman kering $5 \mathrm{~cm}$

- Vegetasi

Bioretensi Bucket II :

- Kerikil $1 \mathrm{~kg}(10 \mathrm{~cm})$

- Ijuk $5 \mathrm{~cm}$

- Pasir kuarsa 5 kg

- Tanah humus $5 \mathrm{~kg}$

- Tanaman kering $5 \mathrm{~cm}$

- Vegetasi 


\section{KILAT}

Vol. 10, No. 1, April 2021, P-ISSN 2089-1245, E-ISSN 2655-4925

DOI: https://doi.org/10.33322/kilat.v10i1.1128

Bioretensi Bucket II :

- Tanah $20 \mathrm{~kg}$

- Tanaman kering $5 \mathrm{~cm}$

- Vegetasi

\subsection{Hasil Bioretensi Bucket}

Hasil penelitian secara eksperimental yang dilakukan pada model Bioretensi bucket dijelaskan pada tabel 2 dibawah ini.

Tabel 2. Hasil pengamatan Bioretensi Bucket

\begin{tabular}{|c|c|c|c|c|c|}
\hline $\begin{array}{c}\text { Bioretensi } \\
\text { Bucket } \\
\text { (BB) }\end{array}$ & $\begin{array}{c}\text { Minggu I } \\
\text { (Volume Air } \\
\text { Masuk/Liter) }\end{array}$ & $\begin{array}{c}\text { Akhir Minggu } \\
\text { I } \\
\text { (Volume Air } \\
\text { Keluar/Liter) }\end{array}$ & $\begin{array}{c}\text { Minggu I } \\
\text { Fisik Air }\end{array}$ & $\begin{array}{c}\text { Minggu II } \\
\text { Fisik Air }\end{array}$ & $\begin{array}{c}\text { Minggu III } \\
\text { Fisik Air }\end{array}$ \\
\hline I & 6 & 3 & $\begin{array}{c}\text { Keruh terdapat } \\
\text { sedimen }\end{array}$ & $\begin{array}{c}\text { Sedikit keruh } \\
\text { masih } \\
\text { terdapat } \\
\text { sedimen }\end{array}$ & Agak Jernih \\
\hline II & 6 & 3 & Keruh & Sedikit keruh & Agak Jernih \\
\hline III & 6 & Tidak keluar & - & - & - \\
\hline
\end{tabular}

Dari hasil pengamatan langsung pada Bioretensi Bucket menggambarkan bahwa hasil kualitas air pada BB I di minggu I dan II masih ditemukan sedimen di dasar botol dan di bagian atas permukaan air. Sedangkan di minggu ke III ada perubahan pada fisik air, yaitu menjadi lebih jernih dan tidak ditemukan sedimen ditunjukka pada gambar 5 .



Gambar 5. BB I Pengamatan Minggu I - III

Pada BB II di minggu I - III menjadi lebih jernih, dengan tidak ditemukannya sedimen di dasar air maupun di permukaan air ditunjukkan pada gambar 6 . 


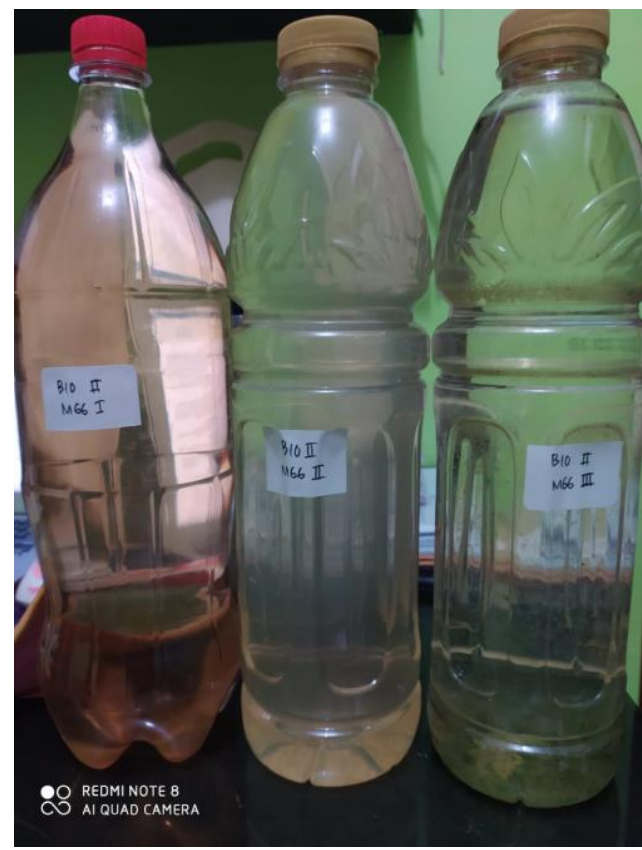

Gambar 6. BB II Pengamatan Minggu I - III

\section{KESIMPULAN DAN SARAN}

Dari hasil penelitian yang dilaksanakan menghasilkan beberapa kesimpulan yaitu bentuk fisik air yang didapat secara pengamatan mata langsung adalah pemakaian pasir kuarsa yang lebih banyak menghasilkan kualitas air yang lebih bersih dibandingkan dengan yang menggunakan pasir kuarsa lebih sedikit.

Fasilitas Bioretensi pada penelitian ini merupakan metode yang ramah lingkungan, karena tidak menggunakan unsur-unsur kimia pada komposisi dari bioretensi bucket.

Fasilitas Bioretention menangkap limpasan air hujan untuk disaring melalui media tanah yang disiapkan. Setelah kapasitas ruang pori tanah dari media terlampaui, air hujan mulai menggenang di permukaan tanah tanam. Air yang terkumpul ini kemudian dapat dikeringkan melalui infiltrasi ke dalam tanah [15].

Sistem Bioretensi ini juga merupakan sebuah teknologi tepat guna. Teknologi tersebut menggunakan sumber-sumber yang tersedia di berbagai tempat serta tidak mengandung unsur kimia baik yang berbentuk cair maupun padat. Teknologi yang diterapkan sesuai dan cocok dengan kondisi sosial ekonomi yang berlaku, artinya mudah dan murah dari komposisi bahan-bahan yang digunakan. Teknologi Bioretensi digunakan bisa memecahkan masalah yang dihadapi masyarakat yaitu kebutuhan akan air bersih yang sudah semakin sulit didapatkan. Serta sistem bioretensi ini mampu dan mudah dipelajari serta diterapkan pada lingkungan masyarakat di Indonesia.

Bioretensi Bucket yang dibuat mudah diaplikasikan pada lokasi penelitian karena bersifat movable (dapat dipindah-pindah) sehingga dapat menyesuaikan kondisi lingkungan sekitar. Sistem bioretensi ini dapat dikoneksikan dengan talang air sehingga dapat mengalirkan air hujan langsung ke sistem bioretensi ini. Jenis vegetasi yang digunakan juga yang banyak terdapat di daerah lokasi penelitian, dalam hal ini menggunakan jenis vegetasi bunga Lavender,

Dari hasil pengamatan air secara fisik memperlihatkan bahwa Teknik Bioretensi yang berupa bioretensi bucket, menghasilkan air yang cenderung lebih jernih pada penyaringan di minggu ke III dibandingkan pada awal-awal penyaringan di minggu I dan II. 


\section{KILAT}

Vol. 10, No. 1, April 2021, P-ISSN 2089-1245, E-ISSN 2655-4925

DOI: https://doi.org/10.33322/kilat.v10i1.1128

Setelah melalui percobaan pada Bioretensi Bucket I menghasilkan 25\% volume air yang outflow, sehingga 75\% air meresap ke dalam sistem Bioretensi Bucket. Ini menyimpulkan bahwa teknologi bioretensi dapat mengurangi volume air limpasan yang berasal dari hujan.

Saran yang diberikan adalah agar dilakukan pemeriksaan kualitas air yang keluar dari bioretensi bucket melalui pengujian air di laboratorium air agar mendapatkan hasil yang akurat mengenai kadar dan nilai Total Suspended Solid (TSS), Total Phosphorus (TP) and Total Nitrogen (TN).

Dapat dilanjutkan penelitian dengan jumlah komposisi isi dari bioretensi bucket yang lebih akurat lagi sehingga mendapatkan hasil kualitas air yang lebih mendetail dan jelas lagi.

\section{UCAPAN TERIMAKASIH}

Ucapan terima kasih disampaikan kepada Institut Teknologi PLN yang telah memberikan kesempatan serta dukungan baik moril dan dana terhadap penelitian yang dilakukan. Khususnya disampaikan juga rasa terima kasih kepada Lembaga Penelitian dan Pengabdian Masyarakat (LPPM) di IT PLN.

\section{DAFTAR PUSTAKA}

[1] J. Liu, D. J. Sample, C. Bell, and Y. Guan, "Review and research needs of bioretention used for the treatment of urban stormwater," Water (Switzerland), vol. 6, no. 4, pp. 1069-1099, 2014.

[2] A. Maryono, Menangani Banjir, Kekeringan, dan Lingkungan. 2014.

[3] A. Maryono, "Eko-Hidraulik Pengelolaan Sungai Ramah Lingkungan, Menanggulangi Banjir dan Kerusakan Lingkungan wilayah Sungai," 2008.

[4] T. M. Muthanna, Bioretention as a sustainable stormwater management option in cold climates. 2007.

[5] X. Li, Z. Liu, C. Wang, T. Yu, and F. Zhou, "The study of bioretention applications for sustainable urban stormwater management in cold climates," Proceedings, Annu. Conf. - Can. Soc. Civ. Eng., vol. 1, no. June, pp. 535-542, 2012.

[6] C. Jiang, J. Li, H. Li, and Y. Li, "Experiment and simulation of layered bioretention system for hydrological performance," J. Water Reuse Desalin., vol. 9, no. 3, pp. 319-329, 2019.

[7] A. . Fallis, "Bioretention systems," J. Chem. Inf. Model., vol. 53, no. 9, pp. 1689-1699, 2013.

[8] M. Shafique, "A review of the bioretention system for sustainable storm water management in urban areas," RMZ-M\&G, vol. 63, pp. 227-236, 2016.

[9] K. Lange, H. Österlund, M. Viklander, and G. T. Blecken, "Metal speciation in stormwater bioretention: Removal of particulate, colloidal and truly dissolved metals," Sci. Total Environ., vol. 724, 2020.

[10] B. Basins, "Policy 11 : Land Development Guidelines,” no. June, pp. 1-43, 2007.

[11] J. Wang, L. H. C. Chua, and P. Shanahan, "Evaluation of pollutant removal efficiency of a bioretention basin and implications for stormwater management in tropical cities," Environ. Sci. Water Res. Technol., vol. 3, no. 1, pp. 78-91, 2017.

[12] A. Mahmoud, T. Alam, M. Yeasir A. Rahman, A. Sanchez, J. Guerrero, and K. D. Jones, "Evaluation of field-scale stormwater bioretention structure flow and pollutant load reductions in a semi-arid coastal climate," Ecol. Eng. X, vol. 1, no. April, p. 100007, 2019.

[13] N. Elyza Muha, L. Mohd Sidek, and M. Jajarmizadeh, "Water Quality Improvement through Reductions of Pollutant Loads on Small Scale of Bioretention System," IOP Conf. Ser. Earth Environ. Sci., vol. 32, no. 1, 2016. 
[14] S. Gülbaz and C. M. Kazezyilmaz-Alhan, "Experimental investigation on hydrologic performance of LID with rainfall-watershed-bioretention system," J. Hydrol. Eng., vol. 22, no. $1,2017$.

[15] Prince George's County, "Bioretention Manual, Environmental Service Division, Department of Environmental Resources,” p. 206, 2007. 